\title{
Updated Perspectives on the Management of Sleep Disorders in the Intensive Care Unit
}

\author{
Georg Nilius ${ }^{1,2}$ \\ Matthias Richter' \\ Maik Schroeder (D) \\ 'Kliniken Essen Mitte, Department of \\ Pneumology, Essen, Germany; ${ }^{2}$ Witten/ \\ Herdecke University, Department of \\ Internal Medicine, Witten, Germany
}

\begin{abstract}
Sleep disorders and circadian dysrhythmias are extremely prevalent in critically ill patients. Impaired sleep has a variety of etiologies, exhibits a wide range of negative effects and, moreover, might deteriorate the patient's prognosis. Despite a number of scientific findings and increased awareness, the importance of sleep optimization is still lower on the list of priories in the intensive care unit (ICU). The techniques of measuring and the evaluation of sleep quantity and quality are a great challenge in the ICU setting. The subjective and objective tools of sleep validation continue to suffer from deficiencies. Treatment approaches to improve the critically ill patient's sleep have focused on nonpharmacologic and pharmacologic strategies with some promising results. But pharmacological interventions alone could not provide sufficient patient benefit. Being aware and knowing of sleep problems and the beneficial effect of the necessary therapies in ICU patients requires greater acceptance. The application of available methods and the development of new methods to prevent sleep disorders in the ICU offer the potential to improve the critically ill patient's outcome.
\end{abstract}

Keywords: ICU, sleep disorders, circadian rhythms

\section{Introduction}

As a result of the 24-hour rotation of the Earth, life has evolved between daylight and a darkness. It has been well known for years that a large number of physiological processes are bound to a 24-hour circadian rhythm (circa-diem, about a day). ${ }^{1}$ The circadian processes are characterized by the length and the amplitude of the cycles. A fully functioning organism requires synchronization between the external environment, the complex structures of different organs, and the metabolism of each cell. The light reactive release of melatonin in the suprachiasmatic nucleus works like a central pacemaker or clock. The basic period of the circadian rhythm is therefore determined by cells of the suprachiasmatic region. ${ }^{2}$ In addition, there are many other central hormonal pacemakers such as cortisol. ${ }^{3}$ Circadian rhythms are driven by so-called clock-genes at the cellular level. These biological rhythms must constantly synchronize with external stimuli like noises, light and especially social necessities. A recently published review provides insights into the circadian mechanism in medicine. ${ }^{4}$ The intrinsic clocks regulate blood pressure and heart rate variations, hormone levels, coagulation and respiratory and exercise capacity. Disorders affecting these complex circadian rhythms have serious consequences for sleep, metabolism, and behavior. We are still in the early state of understanding the complex connections of somatic processes and circadian rhythms. A recent study in
Correspondence: Georg Nilius KEM, Evang Kliniken Essen-Mitte gGmbH, Am Deimelsberg 34 a, Essen, 45276 , Germany

Email g.nilius@kem-med.com 
cardiac surgery has described the interrelationship between circadian rhythmicity and the rate of post-operative complications. The severity of cardiac ischemia was lower, when the surgery was scheduled to be performed in the afternoon. This effect was attributed to a variation in hypoxia-reoxygenation tolerance through circadian genes (Rev-Erba $\alpha){ }^{5}$ Such processes are especially prominent between wakefulness and sleep. There is no doubt, that sleep is a basic physiological need and, in addition to a variety of functions, it is also indispensable for the regeneration and recovery of the body. Numerous studies have demonstrated that patients in the intensive care unit (ICU) commonly experience sleep deprivation and sleep disturbances. $^{6-11}$ The following review presents the current state of knowledge on the importance of sleep and sleep disorders and its management in the ICU. It provides insights into treatment options to improve our patients' sleep.

\section{Physiological Sleep}

Sleep is defined as a recurrent, reversible neurobehavioral state of relative perceptual disconnection and insensitivity to the environment. ${ }^{12}$ Sufficient and restful sleep is considered a biological function and has the primary purpose of physical and psychological regeneration. ${ }^{13}$ The biological need for sleep is highly variable and depends, among other things on genetic factors, age and gender. The time sequence of the sleep-wake cycles is controlled by the circadian rhythm and homeostatic mechanisms (sleeping pressure based on the length of wakefulness phases), which interact. This periodicity is regulated, among other things, by afferents from the retina and consequently by the recognition of light and dark. Studies have shown that the average sleep duration amounts to between 6 and 7 hours, while for older healthy individuals with normal sleep, a sleep duration of 7-8 hours seems appropriate. ${ }^{14-16}$ A recent article demonstrated a J-shaped association between sleep duration and incidence of cardiovascular diseases in adults with minimal risk in the range of 7-8 hours of sleep per night, and a significant increase in mortality for less than 6 hours and more than 10 hours. ${ }^{17}$ The entire process of nocturnal sleep is dynamic and occurs in several cycles, each comprising of a sequence of sleep stages. One cycle usually lasts $90 \pm 20$ minutes. The American Academy of Sleep Medicine (AASM) basically differentiates between two distinct sleep phases, the rapid eye movement (REM) sleep phase, and the NON-REM phase. The latter is further divided into three stages: N1 - lightest sleep, transition from waking to sleep, N2 - light sleep, N3 - deep sleep. Assessment of the sleep stages require monitoring of cerebral activity by an electroencephalogram (EEG), eye movements (electrooculogram [EOG]), and muscle tone (electromyogram [EMG]). Specific waveforms combined with muscle tone and eye activity can be evaluated and represent the sleep stages or wakefulness. As sleep depth increases, the cerebral waves exhibit reduced frequency and higher amplitudes. Stage N1 is considered the lightest sleep or transition from waking to sleep and exhibits alpha and theta waves in the EEG. Stage N2 is characterized as sleep onset with visible sleep spindles (bursts of neural activity in a frequency range of 11-16 $\mathrm{Hz}$ ) and $\mathrm{K}$-complexes (short negative high-voltage peaks, followed by a slower positive complex and a final negative peak). As a characteristic of stage N3, predominantly delta waves (high amplitude with a frequency between 0.5 and $4 \mathrm{~Hz}$ ) are found in the EEG pattern, plus maximum reduction in muscle tone during an increasing sleep depth. ${ }^{18}$ Brief periods of wakefulness are normal and are often associated with no remembered positional changes and usually occur before or after a REM phase. REM EEG patterns resemble the vigilant wakefulness pattern for the most part, next to so-called "saw tooth" waves, muscle atonia and random rapid eye movements. "Normal sleepers" spend about 5\% to $10 \%$ of the time in bed (TIB) in wakefulness. In healthy adults, stage N1 accounts for approximately $5 \%$ of the total sleep time (TST), N2 for $50 \%, \mathrm{~N} 3$ for $12.5 \%$ to $20 \%$, and stage R (REM) for approximately $20-25 \%$. ${ }^{19}$

\section{Methods of Measurement to Determine Sleep in the Intensive Care Unit}

The methods to determine sleep can be divided into different subjective and objective techniques. In general, the implementation of measurement techniques in the ICU is much more difficult than in the sleep laboratory or even in a home environment. The diagnostic process is dependent on the severity of the patient's disease, his consciousness, and the necessary therapeutic and diagnostic interventions. ${ }^{20,21}$

To date, polysomnography (PSG) is considered the gold standard in objective sleep assessment. ${ }^{22}$ During PSG, multiparametric biophysiological signals are recorded under observation of a sleep technician and analyzed integratively. Minimum requirements for a full PSG 
are a 3-leads recording of EEG activity, combined with EOG, EMG, electrocardiogram (ECG), airflow sensors at nares and mouth, respiratory effort (chest and abdominal belt), pulse oximetry and positional measurement. For many years, the quantitative and qualitative evaluation of these signals and the assessment of sleep and sleep stages followed the rules formulated by Rechtschaffen and Kales (R\&K) ${ }^{23}$ Following repeated criticisms, the scoring rules were updated by the AASM in 2007. ${ }^{18}$ The scoring rules were mainly set up for healthy adults and not for patients with severe damage of the central nervous system or the requirement for psychoactive medication. In order to address these issues, other methods were employed, that did not require complex measurement techniques but are still based on the analysis of the EEG, such as the Bispectral Index (BIS) or the SedLine ${ }^{\circledR}$ Brain Function Motor. Also, actigraphy measurements of motoric activity via wrist or ankle band have been established to monitor patient's sleep. An up-to-date overview of measurement methods can be found in the systematic review presented by Richards. ${ }^{20}$

Next to the technical procedures, systematic observation methods were developed to evaluate sleep, like the assessment from nurses and physician staff based on specific patient behavioral activities. These methods are semiobjective, but offer an uncomplicated way to assess sleep in the ICU. Subjective validation options include, but are not limited to, the Richards-Campbell Sleep Questionnaire (RCSQ), the Verran Snyder Harper Sleep Scale (VSH), the coronary care unit (CCU) questionnaire, the Insomnia Severity Index (ISI), and the numerical rating scale (NRS)-Sleep. ${ }^{20,24,25}$

\section{Critical Evaluation of Measurement Methods in the ICU}

All conclusions regarding quantity and quality of sleep require a rather thorough analysis. The mere use of standard criteria for the assessment and evaluation of sleep in critically ill patients is already challenging compared to the situation in the sleep laboratory. Polysomnographic recordings show substantially deviating results, influenced by the typical and partly unavoidable factors of the ICU as well as the patient's neuropathologies. ${ }^{26}$ A PSG recording in the ICU may provide precise information about sleep latency, number of sleep stages and duration, but the EEG recordings can display less K-complexes and sleep spindles $^{27}$ and a low amplitude of delta waves, which leads to a much lower inter-rater reliability regarding determination of sleep stages $(\mathrm{k}=0.19)$ in intensive care patients. ${ }^{28}$ In many cases, classification according to the AASM criteria is not possible at all. Therefore, atypical sleep was defined, characterized by atypical EEG patterns during observed sleep (irregular delta activity and low EMG activity), and pathological wakefulness characterized by slow EEG activity during observed wakefulness. ${ }^{29}$ Recently established, the Odds Ratio product (OPR) provides a continuous estimate of the sleep status as an auxiliary measure of sleep depth and intensity. ${ }^{30}$ Considerable further research is still needed to adequately capture the disturbances (muscle twitching, effects of drugs, electrical interference, etc.) that can occur in the ICU with respect to effects on validity and reliability.

Actigraphy is considered an acceptable method due to its ease and low cost of use, ${ }^{31}$ but it commonly overestimates sleep time, sleep efficiency, and number of awakenings compared to a PSG. ${ }^{20,32}$ A major limit is the detection of sleep/wake movements, since these are already reduced in ICU patients independently of sedation.

Observational sleep assessment also entails methodological problems. Frisk et al reported a low diagnostic discrepancy between patients and nurses in the use of the RCSQ, and Beecroft et al demonstrated a discrepancy between the nurses' elicited sleep assessment and simultaneous PSG findings. ${ }^{32,33}$ Edwards and Schuring on the other hand demonstrated an $81.9 \%$ correlation to the PSG with a 15 min sleep-wake capture interval by nurses. ${ }^{34}$ In addition to lack of important sleep parameters such as sleep latency, arousals, or sleep stages, there is also significant dependency on the observing personnel. Intensive training and sensitization of the nursing staff regarding sleep detection is required. Despite of the possible discrepancy between observer and patient assessment, observational methods represent a viable tool in the ICU. ${ }^{35}$ Due to cognitive impairment on the patient's side, questionnaires for self-monitoring can hardly be used, especially for critically ill patients in the acute phase. Moreover, sufficient reliable data are still missing.

\section{Quantity and Quality of Sleep Disorders in Intensive Care Patients}

The studies that investigated the phenomenon of sleep in the ICU are quite challenging to compare. This is due to the heterogeneity of the patient groups studied, the 
different measurement methods, but also the lack of a uniform definition of good or restful sleep. A recent systematic meta-analysis lists 25 studies in which sleep was determined by means of PSG, of which, however, only 13 studies referred to a period of $24 \mathrm{~h}$ and only 5 studies met the standards of monitored PSG. ${ }^{20}$

Numerous studies have indicated an altered sleep architecture in critically ill patients in the ICU, with high sleep fragmentation and impaired sleep latency due to increased arousals. In addition, an increase in light sleep N1 and N2 as well as a reduction in slow-wave sleep (SWS)/REM sleep was demonstrated. Furthermore, a highly abnormal sleep architecture was recorded by PSG in intensive care patients. $^{21,26,36}$ A temporal disorganization of the circadian rhythmicity and sleep-wake regulation was demonstrated in mechanically ventilated patients receiving continuous intravenous sedation. ${ }^{37}$ The critical illness itself, as well as the use of sedatives, would seem to contribute to some degree to these abnormalities. ${ }^{38,39}$

Using standard R\&K sleep assessments, $\mathrm{K}$ complexes or spindles were absent in almost $45 \%$ of ICU patients' PSG recordings. In addition, further variances, for example in the EEG amplitude, were found, which affect the classification of sleep stages. ${ }^{20}$ The team of Drouot came to the conclusion, that the sleep could not be classified with the standard criteria in 1/3 of the critically ill patients. They described an atypical sleep on the basis of the EEG patterns. This atypical sleep was characterized by prolonged episodes of high amplitudes (50-100 $\mu \mathrm{V})$, continuous and irregular delta activity without superimposed fast frequencies or eye movements, and decreased submental muscle activity. $^{29}$

Patient-related factors such as anxiety, pain, stress or disease-related organ dysfunction, in addition to external disturbing factors from the ward environment, affect not only sleep quality but also sleep quantity. ${ }^{6,21}$ There is a high variability in the findings regarding TST. For example, one study in critically ill patients demonstrated only 5 hours of sleep per 24 hours, divided into a mean of 38 separate episodes with a median duration of 3 minutes. ${ }^{21}$ Another study demonstrated mixed results with mean 24-h TST ranging between 3.2 and 19.4 hours and large intersubject variation with some patients sleeping for only 1 hour. $^{40}$ Half of the TST in ICU patients was in fact registered during the daytime. This can be considered both as a potential consequence of reduced sleep quality but also as abnormality of the circadian rhythm. Alterations of this rhythm can lead to disturbances of the sleep-wake cycle and consequently hinder the patient's recovery through dysregulation of physiological processes. Systemic inflammation can induce disturbances in the circadian rhythmicity. In a group of healthy human subjects, intravenous administration of endotoxin was able to generate a misalignment of the central and peripheral clock through an inflammatory reaction. ${ }^{41}$

It should be mentioned that a chronopathology can be acquired additionally or can exist in advance as a result of the underlying disease, acute symptoms, necessary medication, or pre-existing sleep disorders. The older the patients, the higher the propensity for sleep disturbances may be, consecutively associated with a higher risk of circadian abnormalities in the ICU. ${ }^{42}$

\section{Consequences of Sleep Deficiency}

A frequently underestimated factor for complications in the ICU are numerous sleep disruptions with resulting sleep deprivation, sleep deficiency, and abnormal sleep architecture. Insufficient sleep has been associated with numerous pathophysiologic mechanisms, circadian dysrhythmias, an altered sensorium, and as a result may lead to delayed recovery, prolonged intensive care stay, and, consecutively, increased mortality. ${ }^{11,43,44}$ Several studies reported correlations between sleep disturbances and the incidence of delirium, a common scenario seen in intensive care units. It has been shown, even in healthy subjects, that some of the cognitive consequences of sleep deprivation resemble those of delirium. ${ }^{39}$ Barr found that up to $80 \%$ of ventilated patients were affected, demonstrating prolonged retention and longer-lasting neurocognitive impairment. ${ }^{38}$ In healthy subjects, sleep deprivation causes a marked reduction in inspiratory endurance. The effect is probably based less on changes in peripheral musculature than on a decrease in electrical activity in the motor cortex. ${ }^{45}$ Thus, sleep deprivation has a substantial effect both on respiratory muscles and, consequently, on the weaning process. From the work of Chen and colleagues we know, that sleep deprivation can lead to inspiratory insufficiency even in healthy subjects, who were exposed to intensifying inspiratory stress exercises. ${ }^{46}$

In their study, Thille and colleagues presented a correlation between prolonged weaning in long-term ventilated patients with atypical sleep patterns compared to those with regular patterns. ${ }^{47}$ The SLEEWE study also demonstrated a correlation between increased proportions of pathologic wakefulness, as measured by ORP, and a higher chance of unsuccessful spontaneous breathing 
trials (SBT) and extubation. ${ }^{48}$ Sleep deprivation seems to impair not only neurocognition and respiratory muscle strength but also immune function, resulting in an increased susceptibility to infections. ${ }^{49}$ Recurrent lifethreatening infections are often found in long time ICU patients, considerably impairing the patient's prognosis.

Homeostatic dysregulations are consequences of sleep impairment that should not be ignored. For example, Schmid and colleagues demonstrated an increase in thyroid, cortisol, and norepinephrine levels. This in turn causes a decrease in growth hormone and melatonin levels and a glucose metabolism disorder in the form of insulin resistance. ${ }^{50}$ The latter frequently occurs as one of the comorbidities in critically ill patients anyway, which means that such a correlation with the resulting increased hyperglycemia requires greater attention in intensive care settings. In addition, but not yet sufficiently proven, the possible lack of nocturnal blood pressure drop impairs the cardiovascular function and subsequently has negative effects on a pre-existing heart failure. In summary it can be stated that sleep deprivation itself is a detrimental health factor in the ICU with increased morbidity and mortality rates. ${ }^{51,52}$

\section{Causes of Sleep Disruption at ICU}

To a certain extent, sleep disorders of ICU patients depend on the disease itself, the respective acute symptoms and possible preexisting sleep disturbances. Numerous studies categorize sleep-disrupting causes into environmental and non-environmental factors or external and internal factors. External negative influences are considered to be light and noise exposure, multiple routine care, diagnostic and treatment procedures, and lack of orientation guidance. ${ }^{53,54}$

\section{Noise and Light}

The acoustic and visual disturbances originate, for example, from alarms of the monitoring, perfusion and ventilation systems as well as from the personnel itself. ${ }^{55}$ Dominantly, not only does the intermingled background noise seem to affect the patients but rather the frequency and height of the peak volume, which exceeded $85 \mathrm{dBA}$ up to 16 times per hour. ${ }^{56}$ The 24 -h average sound level was found to be $54.0 \pm 2.4 \mathrm{dBA}$ with no significant differences between day and night. ${ }^{57}$ Next to the patient-involved noise, the remaining acoustic energy was identified as $57 \%$ staff activities, $30 \%$ staff conversations, and $13 \%$ operational noise of life-supporting devices. ${ }^{55}$
According to the World Health Organization (WHO), continuous background noise of $30 \mathrm{~dB}$ and maximum peak noise levels of $45 \mathrm{~dB}$ should be avoided during sleep. ${ }^{58}$ Long-term studies showed almost constant significant exceedances of these set limits in the ICU. ${ }^{26,59}$

Intensive care patients are exposed to unnatural light conditions. During the day, there are considerably lower light intensities compared to the environment, but constant light interruptions during the night. ${ }^{60}$ Light is the key zeitgeber of the circadian system and influences circadian rhythms and the numerous biochemical processes such as melatonin secretion and thus contributes to an optimal sleep pattern and rapid recovery. ${ }^{61,62}$

Medical care and procedures significantly affect patient sleep. Routine procedures such as suctioning, documentation, taking vital signs, or administering medications amount to an average of 7.8 per hour. ${ }^{8}$ A retrospective analysis involving 50 patients in 4 ICU recorded a mean of 42.6 diagnostic or therapeutic procedures in patients between 7 p.m. to 7 a.m. ${ }^{63}$ If the consultations on the patients nearby are included, this disruptive factor increases even more. Surveys among former ICU patients found that noise and the recurrent consultations were the leading sources of disturbance. ${ }^{64}$

\section{Ventilation}

Both invasive and noninvasive ventilation (NIV) will affect the patient's sleep. Regardless of certain limitations arising from a high variance in underlying diseases, patient groups, and types of ventilation (endotracheal tube, tracheostomy, mask), there are many hints that the mode of ventilation will also influence sleep quality and quantity ${ }^{65,66}$ The specific modifications of ventilation are subject of several studies, yet only within a limited patient population. ${ }^{67,68}$ The results were contradictory. Sleep quality was better with assisted controlled ventilation (ACV) compared to pressure-supported ventilation at low pressure rates in patients with acute respiratory failure. Based on this, it was recommended that ventilation in this patient group should be adequately supported; ventilation with a ventilation pressure of $6 \mathrm{~cm} \mathrm{H}_{2} \mathrm{O}$ is not sufficient for this purpose. However, too intensive ventilation causing hypocapnia and subsequent central sleep apnea resulted in increased arousals and consequently reduced sleep quality. ${ }^{67}$

Detected asynchrony between patients and the respirator significantly decreased sleep depth and REM sleep, and led to an increased arousal index with consequently decreased sleep efficiency. ${ }^{65}$ Asynchrony can be 
responsible for up to $19 \%$ of the patient's sleep fragmentation. ${ }^{69}$ One of the most important determining factors affecting patient-ventilator synchronization is the level of sedation. The phenomenon of patient-ventilator asynchrony due to ineffective trigger efforts and high leakage is also a prominent impairing factor in NIV patients. $^{70}$

In general, adverse asynchrony management can potentially affect the weaning process and be associated with prolonged ICU stay and its potential consequences. Moreover, subjective deficits in sleep depth, duration, and quality were noted under pressure controlled ventilation with volume presetting in stable patients compared to no presetting. ${ }^{71}$ A comparison of pressure controlled ventilation with spontaneous triggered ventilation with low and high backup frequencies demonstrated REM sleep reduction in the latter and increased awakening under high backup frequencies. Evidence for a decrease of sleep quality due to high inspiratory ventilation pressure levels have not been found. ${ }^{72}$

Sleep quality was similar on and off the ventilator in difficult-to-wean patients, but sleep quantity was higher with mechanical ventilation. Reconnection during the night may favor sleep efficiency. ${ }^{73}$

Sedatives such as propofol and benzodiazepines act through agonism at the GABA receptor. Apart from prolonging the total sleep time, this has the simultaneous effect of reducing both deep and REM sleep. ${ }^{74,75}$ This may be associated with delirium, resulting in an independent risk for sleep disturbances. ${ }^{76,77}$

Commonly used, catecholamines worsen sleep quality by suppressing the REM phase. ${ }^{78}$ Similarly, opioids also reduce N3 and REM sleep. Beta-blockers, also widely used, suppress REM sleep and can induce nightmares. ${ }^{79}$ A comparative study of ketamine and haloperidol failed to show a difference in prevention of cognitive dysfunction or prevention of postoperative delirium. ${ }^{80}$

\section{Strategies to Improve Sleep in the Intensive Care Unit}

Physiological sleep is multidimensional and consists of various factors such as total sleep time, expectations, environmental awareness, fatigue, and movement. The clinical relevance of sleep for physiological processes and consequently for the recovery of patients is well known. There are numerous pharmacological and nonpharmacological factors causing the occurrence of sleep disorders or the progress of existing sleep disorders, with different effects on the individual critically ill patient. Not least for this reason, the optimal approach to sleep improvement involves individual multi-component strategies. A variety of non-pharmacological adaptations have already been comprehensively evaluated and established in the ICU.

\section{Noise and Light}

Promoting sleep-wake rhythms through various day/night environmental interventions could improve the patients naturally occurring circadian rhythms and were associated with a reduction of the prevalence of delirium. Such interventions comprise sufficient daylight, encouragement of physical and cognitive activities during the day, dimming the lights, closing curtains, providing eye masks and/or earplugs and reducing the nursing activities during the night. ${ }^{81}$ In addition to the necessary reduction of ambient noise, especially at night, and the adaptation of daytime light intensities, another effective and inexpensive approach is the provision of earplugs and/or eye masks. Studies have demonstrated improved sleep quality and a significant reduction of delirium risk with the use of earplugs or a combination of earplugs and eye masks. ${ }^{82}$ Yet, contradictory study results are found regarding an influence on delirium incidence. ${ }^{83,84}$

Music intervention proved to have a relaxing effect and resulted in reductive influence on pain and anxiety. A moderate improvement of sleep quality was found. ${ }^{85}$ The consecutive reduction of the heart rate possibly relates to a protective cardiovascular effect. ${ }^{86}$

Other complementary interventions, such as massages, relaxation techniques, foot baths, valerian acupressure, aromatherapy, and the use of sound masking, may have a benefit on sleep. However, the inconsistent results of the studies show very little evidence. The leading limiting factor in the ICU even in these studies remains the existing clinical heterogeneity to obtain meaningful data or metaanalyses.

\section{Daily Routine}

Another essential approach is to plan the daily routine appropriately by optimizing infrastructural processes of nursing and medical consultations to assess and document vital signs, blood draws, and patient care. A survey of ICU patients by researchers in the Freedman group found these high-frequency contacts to be significantly more sleepdisturbing than noise. ${ }^{64}$ Although this high level of 
surveillance implies confidence both for patients and medical staff, an additional staff sensitization can be used to manage the contacts.

Several authors have demonstrated a benefit from maintaining rest periods for noise reduction and more restful sleep in their studies. ${ }^{87}$ Moreover, visitors and nursing staff expressed high satisfaction with this procedure. However, an improvement in sleep as measured by the RCSQ could not be proven. Environmental noise and the incidence of delirium, on the other hand, were regressive. ${ }^{88}$

\section{Nutrition}

An element that should not be neglected is the appropriate timing of nutrition. Although the guidelines recommend initiation of enteral nutrition as quickly as tolerated over $24-48$ hours in ICU patients, ${ }^{89}$ no information is given on the exact timing of nutritional substitution. It can be assumed, that daytime nutrition with breaks attenuates circadian rhythm disturbances compared to continuous 24hour application. A daily mobilization during daytime may reinforce this potential.

The influence of mechanical ventilation on the quality of sleep has not yet been clearly demonstrated. However, it appears that an appropriate ventilation strategy can help to improve the quality of sleep. It is recommended to establish a personalized synchrony between mechanical ventilation and the patient by optimizing the ventilation mode. Ventilatory support should be constantly customized to prevent consequences of over-support (eg, diaphragmatic atrophy, prolonged ICU stay) or hyperventilation (thresholds of apnea). ${ }^{90}$

During the difficult weaning process in tracheotomized patients, mechanical ventilation was found to significantly prolong sleep duration with a tendency to increase REM and deep sleep compared to spontaneous ventilation. The reduction of work of breathing in this particular patient group is presumably responsible for these effects. ${ }^{73}$ Studies in critically ill patients that compared advanced ventilation modes with conventional modes in terms of synchronization and consecutive influence on sleep fragmentation found inconsistent results. ${ }^{91-93}$

In general, in addition to the ventilation mode, increasing attention should be paid to system components such as volume presets, the ventilatory pressure level, and the backup frequency. The implementation of invasive as well as non-invasive ventilation requires intermittent critical re-evaluation to ensure sufficient synchrony.
Pharmacologic treatment options can be considered once non-pharmacologic interventions have been fully resourced. Numerous drugs administered in the ICU can affect sleep physiology. For example, ketamine, propofol, benzodiazepines, as well as various antidepressants and opioids are under continuous investigation for their potential effects on sleep. Consequently, a careful initial review of the existing medication with possible adaptation should be performed before starting further pharmacological interventions to improve sleep.

Circadian rhythm abnormalities induced by the ICU stay were associated with reduced melatonin levels. With the administration of $10 \mathrm{mg}$ melatonin, Bourne improved nocturnal sleep efficiency, measured by bispectral index (BIS), compared to the placebo group. ${ }^{75}$ The research team led by Nishikimi demonstrated a reduction in delirium incidence (24.4\% from $46.5 \%$ ) and delirium duration when Ramelteon ${ }^{\circledR} \quad(8 \mathrm{mg} / \mathrm{d})$ was administered. Furthermore, subjects experienced considerably less awakening at night, and neurological or other adverse effects. ${ }^{94}$ However, a Cochrane review found insufficient evidence for the use of melatonin to improve sleep in the ICU. ${ }^{95}$

As part of insomnia therapy, low-potency neuroleptics, antidepressants and benzodiazepines are the medications of choice. Due to a lack of data, no statement can be made regarding the sleep-promoting effect of these substances in intensive care patients, especially in those with complex organ damage. However, it is important to address the possible adverse effects, especially anticholinergic side effects, and the great potential of cardiac arrhythmias.

The effect of dexmedetomidine, a selective alpha- 2 agonist, was studied in intensive care patients. Its implementation was associated with the hope of improving the side effects of analgesia on delirium development and circulatory depression. Compared to propofol and benzodiazepines, dexmedetomidine prolonged $\mathrm{N} 2$ and $\mathrm{N} 3$ sleep phases as well as total sleep time and improved subjective sleep quality in pilot studies. ${ }^{96}$ Some evidence for a decrease in postoperative delirium in elderly patients has also been reported. ${ }^{97}$ However, a large multi-center study demonstrated no relevant advantages in either total prognosis or delirium rates compared to propofol and midazolam. ${ }^{98}$ No lower mortality or delirium rates were seen with dexmedetomidine compared to propofol in a very recent study in mechanically ventilated patients with sepsis and mild sedation. ${ }^{99}$ This study reported relevant cognitive dysfunction in about $25 \%$ of the surviving 
patients with a mean age of 60 years, which was not influenced by the selection of the sedative.

In recent years, it has been shown that deep sedation of patients often unnecessarily prolongs invasive ventilation and can be associated with decreased in-hospital survival and also 2-year post follow-up. ${ }^{100,101}$ Clinical approaches of daily sedation breaks in combination with close monitoring of sedation depth were beneficial in terms of duration of ventilation and ICU stay. ${ }^{102-104}$

Overall, a low level of sedating medications ought to be titrated in addition to a close monitoring based on standardized criteria with, for example, sedation protocols, RASS scores, and daily spontaneous awakening trials (SAT), as far as clinically practicable. ${ }^{102}$

However, complete avoidance of sedation in critically ill and mechanically ventilated patients does not improve prognosis. ${ }^{105}$ An adequate analgesia and sedation, depending on clinical necessity, as well as close monitoring are therefore part of the basic therapeutic procedures in critically ill patients.

\section{The $\operatorname{ABCDEF}(G)$ Bundle}

Various components were combined in a multidimensional and interprofessional bundle of actions with regards to hospital survival and delirium and coma-free days. The bundle consists of coordinated awakening and spontaneous breathing coordination and choice of drugs $(\mathrm{ABC})$, delirium screening (D), early mobilization (E), and family engagement (F). It has been shown, that this bundle can successfully be implemented in the intensive care unit, and was associated with improved survival outcome, reduced time on ventilation and coma and delirium frequency. ${ }^{106,107}$ Whether this bundle may also improve sleep quality has not been investigated in the present studies.

Adding the letter "G" for "good sleep" or "generating night sleep" to this bundle for the detection, management and prevention of potential sleep disturbances could represent another interdisciplinary intervention approach in the daily ICU routine. As a consequence, an additional improvement of patient outcome could be expected.

Sleep-promoting actions must be multidimensional and should aim at re-establishing and maintaining the day/ night or circadian rhythms. After the improvement of sleep hygiene and the elimination of potential disturbing factors, the next actions should be built up individually and in a multicomponent way. Ultimately, the entire intensive care process must be aligned with the demands of the circadian rhythm. Whether and which pharmacological approaches are helpful has not yet been sufficiently investigated.

\section{Sleep Disturbances After ICU Treatment}

Survivors of complex intensive care treatment, such as after acute respiratory distress syndrome (ARDS), require long periods of time to return to near-normal life or show significant limitations in quality of life and general vitality even after 5 years have passed. ${ }^{108}$ In this context, sleep problems are reported very frequently. ${ }^{109}$

Finally, a systematic review on the incidence of sleep disturbances after acute hospitalization due to lifethreatening diseases showed a prevalence to sleep disturbances ranging from $55 \%$ to $66.7 \%$ in the first month after discharge, and still $10 \%$ to $60 \%$ after more than 6 months. ${ }^{110}$ The frequency and severity of sleep disturbances depends on pre-existing comorbidities and sleep disorders, but also on in-hospital factors such as the severity of the acute illness, the extent of sleep disturbance during intensive care, pain and sleep medication during intensive care, and the extent of acute stress symptoms. Sleep disturbances seem to have an unfavorable effect on the extent of qualityof-life impairments and psychological comorbidities. Treatment options have barely been reported to date.

\section{Summary}

Circadian dysrhythmias are extremely prevalent in ICU patients. The quantitatively and qualitatively impaired sleep has a variety of etiologies, exhibits a wide range of negative effects and, moreover, might deteriorate the patient's prognosis. Still, little is known about the complex underlying interactions and effects of the pathophysiological, pathopsychological, pharmacological, and environmental elements that contribute to the disturbances of sleep and circadian rhythm in ICU patients. Despite a number of scientific findings and increased awareness, the importance of sleep optimization is still lower on the list of the ICU priorities due to the other leading critical patient conditions.

Moreover, the measurement techniques and the evaluation of sleep quantity and quality represent more than a challenge for the responsible intensive care team. The subjective and objective tools of sleep validation continue to have deficiencies in the ICU setting. Sufficient resources and reliable assessment criteria of sleep macroand microarchitecture are also missing. 
Treatment approaches to improve the critically ill patient's sleep have focused on non-pharmacologic and pharmacologic strategies with some promising results. Yet, just pharmacological interventions alone could not provide sufficient patient benefit.

Being aware and knowing of sleep problems and the beneficial effect of the necessary therapies in intensive care patients requires greater acceptance.

The detection, management, and prevention of sleep disorders and circadian dysrhythmias would ideally be incorporated into daily interdisciplinary rounds. Continued large multi-center studies are required to develop and implement multidisciplinary strategies for more sophisticated sleep assessment in the ICU, and the implementation of standardized environmental conditions. The application of available methods and the development of new methods to prevent sleep disorders in the ICU offer the potential to improve the critically ill patient's outcome.

\section{Disclosure}

Prof. Dr Georg Nilius report I have perceived funds from Löwenstein, Fisher \& Paykel, ResMed and JAZZ Pharma. The projects are not associated with the submitted publication. The authors report no other conflicts of interest in this work.

\section{References}

1. Aschoff J. Circadian rhythms in man. Science. 1965;148 (3676): 1427-1432. doi:10.1126/science.148.3676.1427

2. Ralph MR, Foster RG, Davis FC, Menaker M. Transplanted suprachiasmatic nucleus determines circadian period. Science. 1990;247 (4945):975-978. doi:10.1126/science.2305266

3. Perreau-Lenz S, Pévet P, Buijs RM, Kalsbeek A. The biological clock: the bodyguard of temporal homeostasis. Chronobiol Int. 2004;21 (1):1-25. doi:10.1081/cbi-120027984

4. Allada R, Bass J, Longo DL. Circadian mechanisms in medicine. $N$ Engl J Med. 2021;384(6):550-561. doi:10.1056/NEJMra1802 337

5. Montaigne D, Marechal X, Modine T, et al. Daytime variation of perioperative myocardial injury in cardiac surgery and its prevention by Rev-Erb $\alpha$ antagonism: a single-centre propensity-matched cohort study and a randomised study. Lancet. 2018;391(10115):59-69. doi:10.1016/S0140-6736(17)32132-3

6. Bihari S, McEvoy RD, Mathson E, Kim S, Woodman RJ, Bersten AD. Factors affecting sleep quality of patients in intensive care unit. $J$ Clin Sleep Med. 2012;8(03):301-307. doi:10.5664/jcsm.1920

7. Meyer TJ, Eveloff SE, Bauer MS, Schwartz WA, Hill NS, Millman RP. Adverse environmental conditions in the respiratory and medical ICU settings. Chest. 1994;105(4):1211-1216. doi:10.13 78/chest.105.4.1211

8. Gabor JY, Cooper AB, Crombach SA, et al. Contribution of the intensive care unit environment to sleep disruption in mechanically ventilated patients and healthy subjects. Am J Respir Crit Care Med. 2003;167(5):708-715. doi:10.1164/rccm.2201090
9. Tembo AC, Parker V, Higgins I. The experience of sleep deprivation in intensive care patients: findings from a Larger Hermeneutic Phenomenological Study. Intensive Crit Care Nurs. 2013;29(6):310-316. doi:10.1016/j.iccn.2013. 05.003

10. Friese RS, Diaz-Arrastia R, McBride D, Frankel H, Gentilello LM. Quantity and quality of sleep in the surgical intensive care unit: are our patients sleeping? J Trauma. 2007;63(6):1210-1214. doi:10.1097/TA.0b013e31815b83d7

11. Wang J, Greenberg H. Sleep and the ICU. Open Crit Care Med J. 2013;6(1):80-87. doi:10.2174/1874828701306010080

12. Carskadon MA, Dement WC. Monitoring and staging human sleep. In: Kryger MH, Roth T, Dement WC, editors. Principles and Practice of Sleep Medicine. 5th ed. St. Louis: Elsevier Saunders; 2011:16-26.

13. Ritmala-Castren M, Virtanen I, Leivo S, Kaukonen KM, LeinoKilpi H. Sleep and nursing care activities in an intensive care unit. Nurs Health Sci. 2015;17(3):354-361. Epub 2015 Mar 18. PMID: 25786544. doi:10.1111/nhs.12195

14. Ferrie JE, Shipley MJ, Cappuccio FP, et al. A prospective study of change in sleep duration: associations with mortality in the Whitehall II cohort. Sleep. 2007;30(12):1659-1666. doi:10.1093/ sleep/30.12.1659

15. Kripke DF, Garfinkel L, Wingard DL, Klauber MR, Marler MR. Mortality associated with sleep duration and insomnia. Arch Gen Psychiatry. 2002;59(2):131-136. doi:10.1001/archpsyc.59.2.131

16. Hirshkowitz M, Whiton K, Albert SM, et al. National sleep foundation's sleep time duration recommendations: methodology and results summary. Sleep Health. 2015;1(1):40-43. doi:10.1016/j.sleh.2014.12.010

17. Kwok CS, Kontopantelis E, Kuligowski G, et al. Self-reported sleep duration and quality and cardiovascular disease and mortality: a dose-response meta-analysis. J Am Heart Assoc. 2018;7 (15):e008552. doi:10.1161/JAHA.118.008552

18. Iber C, Ancoli-Israel S, Chesson AL Jr, Quan SF. AASM Manual for the Scoring of Sleep and Associated Events: Rules, Terminology and Technical Specifications. 1st ed. Westchester, IL: American Academy of Sleep Medicine; 2007.

19. Keenan S, Hirshkowitz M. Monitoring and staging human sleep. In: Kryger MH, Roth T, Dement WC, editors. Principles and Practice of Sleep Medicine. 5th ed. St. Louis: Elsevier Saunders; 2011:1602-1609.

20. Richards KC, Wang YY, Jun J, Ye L. A systematic review of sleep measurement in critically ill patients. Front Neurol. 2020;11:542529. doi:10.3389/fneur.2020.542529

21. Elliott R, McKinley S, Cistulli P, Fien M. Characterisation of sleep in intensive care using 24-hour polysomnography: an Observational Study. Crit Care. 2013;17(2):R46. doi:10.1186/ cc12565

22. Kushida CA, Littner MR, Morgenthaler T, et al. Practice parameters for the indications for polysomnography and related procedures: an update for 2005. Sleep. 2005;28(4):499-521. doi:10.1093/sleep/28.4.499

23. Rechtschaffen A, Kales A. A manual of standardized terminology, techniques and scoring system for sleep stages of human subjects. In: Rechtschaffen A, Kales A, editors. Neurological Information Network. Bethesda, MD: U. S.National Institute of Neurological Diseases and Blindness; 1968.

24. Storti LJ, Servantes DM, Borges M, et al. Validation of a novel sleep-quality questionnaire to assess sleep in the coronary care unit: a Polysomnography Study. Sleep Med. 2015;16(8):971-975. doi:10.1016/j.sleep.2015.03.014

25. Ritmala-Castren M, Lakanmaa RL, Virtanen I, Leino-Kilpi H. Evaluating adult patients' sleep: an integrative literature review in critical care. Scand J Caring Sci. 2014;28(3):435-448. doi:10.1111/scs. 12072 
26. Freedman NS, Gazendam J, Levan L, Pack AI, Schwab RJ. Abnormal sleep/wake cycles and the effect of environmental noise on sleep disruption in the intensive care unit. Am J Respir Crit Care Med. 2001;163(2):451-457. doi:10.1164/ajrccm.163. 2.9912128

27. Watson PL, Pandharipande P, Gehlbach BK, et al. Atypical sleep in ventilated patients: empirical electroencephalography findings and the path toward revised ICU sleep scoring criteria. Crit Care Med. 2013;41(8):1958-1967. doi:10.1097/CCM.0b013e31828a $3 \mathrm{f} 75$

28. Ambrogio C, Koebnick J, Quan SF, Ranieri M, Parthasarathy S. Assessment of sleep in ventilator-supported critically III patients. Sleep. 2008;31(11):1559-1568. doi:10.1093/sleep/31.11.1559

29. Drouot X, Roche-Campo F, Thille AW, et al. A new classification for sleep analysis in critically ill patients. Sleep Med. 2012;13 (1):7-14. doi:10.1016/j.sleep.2011.07.012

30. Younes M, Schweitzer PK, Griffin KS, Balshaw R, Walsh JK. Comparing two measures of sleep depth/intensity. Sleep. 2020;43 (12):zsaa127. doi:10.1093/sleep/zsaa127

31. Smith MT, McCrae CS, Cheung J, et al. Use of actigraphy for the evaluation of sleep disorders and circadian rhythm sleep- wake disorders: an American Academy of Sleep Medicine systematic review, meta-analysis, and GRADE assessment. $J$ Clin Sleep Med. 2018;14(07):1209-1230. doi:10.5664/jcsm.7228

32. Beecroft JM, Ward M, Younes M, Crombach S, Smith O, Hanly PJ. Sleep monitoring in the intensive care unit: comparison of nurse assessment, actigraphy and polysomnography. Intensive Care Med. 2008;34(11):2076-2083. doi:10.1007/s00134-008$1180-\mathrm{y}$

33. Frisk U, Nordström G. Patients' sleep in an intensive care unitpatients' and nurses' perception. Intensive Crit Care Nurs. 2003;19(6):342-349. doi:10.1016/s0964-3397(03)00076-4

34. Edwards GB, Schuring LM. Pilot study: validating staff nurses' observations of sleep and wake states among critically ill patients, using polysomnography. Am J Crit Care. 1993;2(2):125-131. doi:10.4037/ajcc1993.2.2.125

35. Aitken LM, Elliott R, Mitchell M, et al. Sleep assessment by patients and nurses in the intensive care: an Exploratory Descriptive Study. Aust Crit Care. 2017;30(2):59-66. doi:10.1016/j.aucc.2016.04.001

36. Cooper AB, Thornley KS, Young GB, Slutsky AS, Stewart TE, Hanly PJ. Sleep in critically ill patients requiring mechanical ventilation [published correction appears in Chest 2001;119(3):993]. Chest. 2000;117(3):809-818. doi:10.1378/ chest.117.3.809

37. Gehlbach BK, Chapotot F, Leproult R, et al. Temporal disorganization of circadian rhythmicity and sleep-wake regulation in mechanically ventilated patients receiving continuous intravenous sedation. Sleep. 2012;35(8):1105-1114. doi:10.5665/sleep.1998

38. Barr J, Fraser GL, Puntillo K, et al. Clinical practice guidelines for the management of pain, agitation, and delirium in adult patients in the intensive care unit. Crit Care Med. 2013;41 (1):263-306. doi:10.1097/CCM.0b013e3182783b72

39. Weinhouse GL, Schwab RJ, Watson PL, et al. Bench-to-bedside review: delirium in ICU patients - importance of sleep deprivation. Crit Care. 2009;13(6):234. doi:10.1186/cc8131

40. Hardin KA. Sleep in the ICU: potential mechanisms and clinical implications. Chest. 2009;136(1):284-294. ISSN 0012-3692. doi: 10.1378/chest.08-1546

41. Haimovich B, Calvano J, Haimovich AD, et al. In vivo endotoxin synchronizes and suppresses clock gene expression in human peripheral blood leukocytes. Crit Care Med. 2010;38 (3):751-758. doi:10.1097/CCM.0b013e3181cd131c

42. Nakamura TJ, Nakamura W, Yamazaki S, et al. Age-related decline in circadian output. $J$ Neurosci. 2011;31(28):10 201-10205. doi:10.1523/JNEUROSCI.0451-11.2011
43. Kamdar BB, Niessen T, Colantuoni E, et al. Delirium transitions in the medical ICU: exploring the role of sleep quality and other factors. Crit Care Med. 2015;43(1):135-141. doi:10.1097/ CCM.0000000000000610

44. Tilias I, Wilcox ME. Sleep and circadian rhythm in critical illness. Crit Care. 2019;23(1):82. doi:10.1186/S13054-01923-66-0

45. Rault C, Sangaré A, Diaz V, et al. Impact of sleep deprivation on respiratory motor output and endurance. A Physiological Study. Am J Respir Crit Care Med. 2020;201(8):976-983. PMID: 31810378. doi:10.1164/rccm.201904-0819OC

46. Chen HI, Tang YR. Sleep loss impairs inspiratory muscle endurance. Am Rev Respir Dis. 1989;140(4):907-909. doi:10.1164/ajrccm/140.4.907

47. Thille AW, Reynaud F, Marie D, et al. Impact of sleep alterations on weaning duration in mechanically ventilated patients: a Prospective Study. Eur Respir J. 2018;51(4):1702465. doi:10.1183/13993003.02465-2017

48. Dres M, Younes M, Rittayamai N, et al. Sleep and pathological wakefulness at the time of liberation from mechanical ventilation (SLEEWE). A Prospective Multicenter Physiological Study. Am $J$ Respir Crit Care Med. 2019;199(9):1106-1115. PMID: 30818966. doi:10.1164/rccm.201811-2119OC

49. Besedovsky L, Lange T, Born J. Sleep and immune function. Pflugers Arch. 2012;463(1):121-137. Epub 2011 Nov 10. PMID: 22071480; PMCID: PMC3256323. doi:10.1007/s00424011-1044-0

50. Schmid SM, Hallschmid M, Jauch-Chara K, Bandorf N, Born J, Schultes B. Sleep loss alters basal metabolic hormone secretion and modulates the dynamic counterregulatory response to hypoglycemia. J Clin Endocrinol Metab. 2007;92(8):3044-3051. doi:10.1210/jc.2006-2788

51. Grandner MA, Hale L, Moore M, Patel NP. Mortality associated with short sleep duration: the evidence, the possible mechanisms, and the future. Sleep Med Rev. 2010;14(3):191-203. doi:10.1016/ j.smrv.2009.07.006

52. Grandner MA, Sands-Lincoln MR, Pak VM, Garland SN. Sleep duration, cardiovascular disease, and proinflammatory biomarkers. Nat Sci Sleep. 2013;5:93-107. doi:10.2147/NSS. S31063

53. Walder B, Haase U, Rundshagen I. Schlafstörungen bei kritisch kranken patienten [Sleep disturbances in critically ill patients]. Anaesthesist. 2007;56(1):7-17. doi:10.1007/s00101-006-1086-4

54. Parthasarathy S. Sleep during mechanical ventilation. Curr Opin Pulm Med. 2004;10(6):489-494. doi:10.1097/01.mcp.000014 3691.94442.fa

55. Park M, Kohlrausch A, de Bruijn W, de Jager P, Simons K. Analysis of the soundscape in an intensive care unit based on the annotation of an audio recording. J Acoust Soc Am. 2014;135 (4):1875-1886. PMID: 25234986. doi:10.1121/1.4868367

56. Darbyshire JL, Young JD. An investigation of sound levels on intensive care units with reference to the WHO guidelines. Crit Care. 2013;17(5):R187. PMID: 24005004; PMCID: PMC405 6361. doi:10.1186/cc12870

57. Simons KS, Verweij E, Lemmens PMC, et al. Noise in the intensive care unit and its influence on sleep quality: a multicenter observational study in Dutch intensive care units. Crit Care. 2018;22(1):250. PMID: 30290829; PMCID: PMC6173893. doi:10.1186/s13054-018-2182-y

58. Berglund B, Lindvall T, Schwela DH. Guidelines for Community Noise Geneva. Geneva, Switzerland: World Health Organization; 1999.

59. Salandin A, Arnold J, Kornadt O. Noise in an intensive care unit. $J$ Acoust Soc Am. 2011;130(6):3754-3760. doi:10.1121/1.3655884

60. Durrington HJ. Light intensity on intensive care units - a short review. Intensive Crit Care Nurs. 2017;3(02):2. doi:10.21767/ 2471-8505.100082 
61. Kamdar BB, Needham DM, Collop NA. Sleep deprivation in critical illness: its role in physical and psychological recovery. $J$ Intensive Care Med. 2012;27(2):97-111. doi:10.1177/ 0885066610394322

62. Engwall M, Fridh I, Johansson L, Bergbom I, Lindahl B. Lighting, sleep and circadian rhythm: an intervention study in the intensive care unit. Intensive Crit Care Nurs. 2015;31 (6):325-335. doi:10.1016/j.iccn.2015.07.001

63. Tamburri LM, DiBrienza R, Zozula R, Redeker NS. Nocturnal care interactions with patients in critical care units. Am J Crit Care. 2004;13(2):102-115. doi:10.4037/ajcc2004.13.2.102

64. Freedman NS, Kotzer N, Schwab RJ. Patient perception of sleep quality and etiology of sleep disruption in the intensive care unit. Am J Respir Crit Care Med. 1999;159(4 Pt 1):1155-1162. doi:10.1164/ajrccm.159.4.9806141

65. Guo YF, Sforza E, Janssens JP. Respiratory patterns during sleep in obesity-hypoventilation patients treated with nocturnal pressure support: a preliminary report. Chest. 2007;131(4):1090-1099. doi:10.1378/chest.06-1705

66. Bosma K, Ferreyra G, Ambrogio C, et al. Patient-ventilator interaction and sleep in mechanically ventilated patients: pressure support versus proportional assist ventilation. Crit Care Med. 2007;35(4):1048-1054. doi:10.1097/01.CCM.0000260055.6423 5.7C

67. Parthasarathy S, Tobin MJ. Effect of ventilator mode on sleep quality in critically ill patients. Am J Respir Crit Care Med. 2002;166(11):1423-1429. doi:10.1164/rccm.200209-999OC

68. Toublanc B, Rose D, Glérant JC, et al. Assist-control ventilation vs. low levels of pressure support ventilation on sleep quality in intubated ICU patients. Intensive Care Med. 2007;33 (7):1148-1154. doi:10.1007/s00134-007-0659-2

69. Córdoba-Izquierdo A, Drouot X, Thille AW, et al. Sleep in hypercapnic critical care patients under noninvasive ventilation: conventional versus dedicated ventilators. Crit Care Med. 2013;41(1):60-68. doi:10.1097/CCM.0b013e31826764e3

70. Nilius G, Katamadze N, Domanski U, Schroeder M, Franke KJ. Non-invasive ventilation with intelligent volume-assured pressure support versus pressure-controlled ventilation: effects on the respiratory event rate and sleep quality in COPD with chronic hypercapnia. Int $J$ Chron Obstruct Pulmon Dis. 2017;12:1039-1045. doi:10.2147/COPD.S126970

71. Janssens JP, Metzger M, Sforza E, et al. Impact of volume targeting on efficacy of bi-level non-invasive ventilation and sleep in obsesity-hypoventilation. Resir Med. 2009;103 (2):165-172. doi:10.1016/j.rmed.2008.03.013

72. Dreher M, Ekkernkamp E, Walterspacher S, et al. Noninvasive ventilation in COPD: impact of inspiratory pressure levels on sleep quality. Chest. 2011;140(4):939-945. doi:10.1378/chest.110253

73. Roche-Campo F, Thille AW, Drouot X, et al. Comparison of sleep quality with mechanical versus spontaneous ventilation during weaning of critically ill tracheostomized patients. Crit Care Med. 2013;41(7):1637-1644. doi:10.1097/CCM.0b013e31828 $7 \mathrm{f} 569$

74. Pandharipande P, Ely EW. Sedative and analgesic medications: risk factors for delirium and sleep disturbances in the critically ill. Crit Care Clin. 2006;22(2):313-vii. doi:10.1016/j.ccc.2006.02. 010

75. Bourne RS, Mills GH. Sleep disruption in critically ill patients pharmacological considerations. Anesthesia. 2004;59(4):374-384. doi:10.1111/j.1365-2044.2004.03664.x

76. Devlin JW, Skrobik Y, Gélinas C, et al. Clinical practice guidelines for the prevention and management of pain, agitation/ sedation,delirium, immobility, and sleep disruption in adult patients in the ICU. Crit Care Med. 2018;46(9):e825-e873. doi:10.1097/ CCM.0000000000003299
77. Trompeo AC, Vidi Y, Locane MD, et al. Sleep disturbances in the critically ill patients: role of delirium and sedative agents. Minerva Anestesiol. 2011;77(6):604-612.

78. Kondili E, Alexopoulou C, Xirouchaki N, Georgopoulos D. Effects of propofol on sleep quality in mechanically ventilated critically ill patients: a physiological study. Intensive Care Med. 2012;38(10):1640-1646. doi:10.1007/s00134-012-2623-z

79. Bourne RS. Delirium and use of sedation agents in intensive care. Nurs Crit Care. 2008;13(4):195-202. doi:10.1111/j.1478-5153. 2008.00278.x

80. Hollinger A, Rüst CA, Riegger H, et al. Ketamine vs. haloperidol for prevention of cognitive dysfunction and postoperative delirium: a Phase IV multicentre randomised placebo-controlled double-blind clinical trial. J Clin Anesth. 2021;68:110099. Epub 2020 Oct 22. PMID: 33120302. doi:10.1016/j.jclinane.2020.11 0099

81. Tonna JE, Dalton A, Presson AP, et al. The effect of a quality improvement intervention on sleep and delirium in critically ill patients in a surgical intensive care unit. Chest. 2021:S00123692(21)00548-1. Epub ahead of print. PMID: 33773988. doi:10.1016/j.chest.2021.03.030

82. Litton E, Carnegie V, Elliott R, Webb SA. The efficacy of earplugs as a sleep hygiene strategy for reducing delirium in the ICU: a systematic review and meta-analysis. Crit Care Med. 2016;44(5):992-999. doi:10.1097/CCM.0000000000001557

83. Verceles AC, Liu X, Terrin ML, et al. Ambient light levels and critical care outcomes. J Crit Care. 2013;28(110):e111-8. doi:10.1016/j.jcrc.2012.04.012

84. Van Rompaey B, Elseviers MM, Schuurmans MJ, ShortridgeBaggett LM, Truijen S, Bossaert L. Risk factors for delirium in intensive care patients: a Prospective Cohort Study. Crit Care. 2009;13(3):R77. doi:10.1186/cc7892

85. Bradt J, Dileo C. Musikinterventionen für beatmete Patienten. Cochrane Database Syst Rev. 2014. PUBMED: 25490233. doi:10.1002/14651858.CD006902.pub3

86. Su CP, Lai HL, Chang ET, Yiin LM, Perng SJ, Chen PW. A randomized controlled trial of the effects of listening to non-commercial music on quality of nocturnal sleep and relaxation indices in patients in medical intensive care unit. $J \quad A d v \quad$ Nurs. 2013;69(6):1377-1389. doi:10.1111/j.13652648.2012.06130.x

87. Gardner G, Collins C, Osborne S, Henderson A, Eastwood M. Creating a therapeutic environment: a non-randomised controlled trial of a quiet time intervention for patients in acute care. Int J Nurs Stud. 2009;46(6):778-786. Epub 2009 Jan 23. PMID: 19167711. doi:10.1016/j.ijnurstu.2008.12.009

88. Kamdar BB, King LM, Collop NA, et al. The effect of a quality improvement intervention on perceived sleep quality and cognition in a medical ICU. Crit Care Med. 2013;41(3):800-809. doi:10.1097/CCM.0b013e3182746442

89. McClave SA, Taylor BE, Martindale RG, et al. Guidelines for the provision and assessment of nutrition support therapy in the adult critically ill patient: Society of Critical Care Medicine (SCCM) and American Society for Parenteral and Enteral Nutrition (A.S.P.E.N.) [published correction appears in JPEN J Parenter Enteral Nutr. 2016 Nov;40(8):1200]. JPEN $J$ Parenter Enteral Nutr. 2016;40(2):159-211. doi:10.1177/ 0148607115621863

90. Vaporidi K, Akoumianaki E, Telias E, et al. Respiratory drive in critical ill patients. Pathophysiology and clinical implications. $A M$ $J$ Respir Crit Care Med. 2020;201(1):20-32. doi:10.1164/ rccm.201903-0596So

91. Alexopoulou C, Kondili E, Plataki M, Georgopoulos D. Patient- ventilator synchrony and sleep quality with proportional assist and pressure support ventilation. Intensive Care Med. 2013;39. 
92. Alexopoulou C, Kondili E, Vakouti E, Klimathianaki M, Prinianakis G, Georgopoulos D. Sleep during proportional-assist ventilation with load-adjustable gain factors in critically ill patients. Intensive Care Med. 2007;33(7):1139-1147. doi:10.1007/s00134-007-0630-2

93. Delisle S, Ouellet P, Bellemare P, Tétrault JP, Arsenault P. Sleep quality in mechanically ventilated patients: comparison between NAVA and PSV modes. Ann Intensive Care. 2011;1:42. doi:10.1186/2110-5820-1-42

94. Nishikimi M, Numaguchi A, Takahashi K, et al. Effect of administration of ramelteon, a melatonin receptor agonist, on the duration of stay in the ICU: a single-center randomized placebo-controlled trial. Crit Care Med. 2018;46(7):1099-1105. doi:10.1097/CCM.0000000000003132

95. Lewis SR, Pritchard MW, Schofield-Robinson OJ, Alderson P, Smith AF. Melatonin for the promotion of sleep in adults in the intensive care unit. Cochrane Database Syst Rev. 2018;5(5): CD012455. PMID: 29746721; PMCID: PMC6353085. doi:10.10 02/14651858.CD012455.pub2

96. Akeju O, Hobbs LE, Gao L, et al. Dexmedetomidine promotes biomimetic non-rapid eye movement stage 3 sleep in humans: a pilot study. Clin Neurophysiol. 2018;129(1):69-78. doi:10.1016/ j.clinph.2017.10.005

97. Su X, Meng ZT, Wu XH, et al. Dexmedetomidine for prevention of delirium in elderly patients after non-cardiac surgery: a randomised, double-blind, placebo-controlled trial. Lancet. 2016;388(10054):1893-1902. doi:10.1016/S0140-6736(16)305 80-3

98. Shehabi Y, Howe BD, Bellomo R; ANZICS Clinical Trials Group and the SPICE III Investigators. Early sedation with dexmedetomidine in critically ill patients. $N$ Engl J Med. 2019;380 (26):2506-2517. Epub 2019 May 19. PMID: 31112380. doi:10.1056/NEJMoa1904710

99. Hughes CG, Mailloux PT, Devlin JW. Dexmedetomidine or propofol for sedation in mechanically ventilated adults with sepsis. $N$ Engl J Med. 2021;384(15):1424-1436. doi:10.1056/NEJMoa 2024922

100. Shehabi Y, Bellomo R, Reade MC, et al.; Sedation Practice in Intensive Care Evaluation (SPICE) Study Investigators; ANZICS Clinical Trials Group. Early intensive care sedation predicts long-term mortality in ventilated critically ill patients. $\mathrm{Am}$ J Respir Crit Care Med. 2012;186(8):724-731. Epub 2012 Aug 2. PMID: 22859526. doi:10.1164/rccm.201203-0522OC
101. Balzer F, Weiß B, Kumpf O, et al. Early deep sedation is associated with decreased in-hospital and two-year follow-up survival. Crit Care. 2015;19(1):197. PMID: 25928417; PMCID: PMC4435917. doi:10.1186/s13054-015-0929-2

102. Girard TD, Kress JP, Fuchs BD, et al. Efficacy and safety of a paired sedation and ventilator weaning protocol for mechanically ventilated patients in intensive care (awakening and breathing controlled trial): a randomised controlled trial. Lancet. 2008;371(9607):126-134. doi:10.1016/S0140-6736(08)60105-1

103. Kress JP, Pohlman AS, O'Connor MF, Hall JB. Daily interruption of sedative infusions in critically ill patients undergoing mechanical ventilation. $N$ Engl J Med. 2000;342(20):1471-1477. doi:10.1056/NEJM200005183422002

104. Strøm T, Martinussen T, Toft P. A protocol of no sedation for critically ill patients receiving mechanical ventilation: a randomised trial. Lancet. 2010;375(9713):475-480. doi:10.10 16/S0140-6736(09)62072-9

105. Olsen HT, Nedergaard HK, Toft P. Nonsedation or light sedation in critically ill, mechanically ventilated patients. reply. $N$ Engl $J$ Med. 2020;382(26):e107. doi:10.1056/NEJMc2011055

106. Barnes-Daly MA, Phillips G, Ely EW. Improving hospital survival and reducing brain dysfunction at seven California community hospitals: implementing PAD guidelines via the ABCDEF bundle in 6064 patients. Crit Care Med. 2017;45(2):171-178. doi:10.1097/CCM.0000000000002149

107. Pun BT, Balas MC, Barnes-Daly MA, et al. Caring for critically ill patients with the ABCDEF bundle: results of the ICU liberation collaborative in over 15,000 adults. Crit Care Med. 2019;47 (1):3-14. doi:10.1097/CCM.0000000000003482

108. Herridge MS, Tansey CM, Matté A, et al. Functional disability 5 years after acute respiratory distress syndrome. $N$ Engl $\mathrm{J} \mathrm{Med}$. 2011;364(14):1293-1304. doi:10.1056/NEJMoa1011802

109. Krumholz HM. Post-hospital syndrome - an acquired, transient condition of generalized risk. $N$ Engl J Med. 2013;368:100-102. doi:10.1056/NEJMp1212324

110. Altman MT, Knauert MP, Pisani MA. Sleep disturbance after hospitalization and critical illness: a systematic review. Ann $\mathrm{Am}$ Thorac Soc. 2017;14(9):1457-1468. doi:10.1513/AnnalsATS.201 702-148SR

\section{Publish your work in this journal}

Nature and Science of Sleep is an international, peer-reviewed, open access journal covering all aspects of sleep science and sleep medicine, including the neurophysiology and functions of sleep, the genetics of sleep, sleep and society, biological rhythms, dreaming, sleep disorders and therapy, and strategies to optimize healthy sleep.
The manuscript management system is completely online and includes a very quick and fair peer-review system, which is all easy to use. Visit http://www.dovepress.com/testimonials.php to read real quotes from published authors. 